\title{
Pattern of injury of blunt trauma abdomen in rural population
}

\author{
Shailendra Pal Singh ${ }^{1}$, Vipin Gupta ${ }^{1}$, Somendra Pal Singh ${ }^{1}$, Rajesh Verma $^{1}$, Prashant Gupta ${ }^{1}$, \\ Anil Kumar ${ }^{1}$, Dinesh Bagaria ${ }^{1}$, Jigyasa pandey ${ }^{2}$, Gyanendra Kumar', Mohan Singh ${ }^{1}$
}

\author{
${ }^{1}$ Department of Surgery, UP Rural Institute of Medical Sciences and Research, Saifai, Etawah, UP, India \\ ${ }^{2}$ Department of Radiology, MAYO, Institute of Medical Sciences, Lucknow, India
}

Received: 22 March 2016

Accepted: 28 March 2016

\section{*Correspondence:}

Dr. Somendra Pal Singh,

E-mail: somendrachauhan@ @otmail.com

Copyright: ( $)$ the author(s), publisher and licensee Medip Academy. This is an open-access article distributed under the terms of the Creative Commons Attribution Non-Commercial License, which permits unrestricted non-commercial use, distribution, and reproduction in any medium, provided the original work is properly cited.

\section{ABSTRACT}

Background: Blunt trauma abdomen accounts for the majorities of abdominal injuries seen in emergency department. Majorities of blunt trauma abdomen cases (75\%) are related to motor vehicle collision. The present study is conducted to study different organ injuries that are encountered in blunt injury to abdomen, the clinical manifestation, diagnostic approaches, and management of different organ injuries, associated morbidity and mortality and to improve our approach in reducing morbidity and mortality.

Methods: A total of 110 patients of blunt trauma abdomen were admitted in emergency of UP Rural Institute of Medical Sciences and Research, Saifai Etawah, UP, India within 1 year. Out of these 110 patients, 100 consecutive cases having history of blunt trauma abdomen and with regard to etiologies, clinical manifestations, diagnostic modalities, management and complication were taken for study.

Results: Road traffic accidents were most common cause of blunt injury to abdomen (60\%). People in 5-40 years were more prone to trauma. Males were predominantly involved. Pain abdomen was most common symptom $(100 \%)$. Tenderness $(95 \%)$ is most common sign. Mean duration of hospital stay for operated cases was 16 days and for non-operated cases was 8.11 days. USG was $81 \%$ sensitive and $100 \%$ specific in diagnosing solid organ injury. Operative management was done in $60 \%$ cases. Mortality was $5 \%$.

Conclusions: Injuries to solid organs are clinically difficult to diagnose. Repeated clinical examinations and use of appropriate diagnostic modalities holds the key in management. Non- operative management for solid organ injuries in a haemodynamically stable patient is a better option as there will be less hospital stay and less complication.

Keywords: Blunt trauma abdomen, Solid organ injury, Hollow viscous injury, Non-operative group, Post-operative complications

\section{INTRODUCTION}

Trauma is the most common cause of death in young patients. The abdomen is third most common injured region with surgery required in about $25 \%$ cases. ${ }^{1}$ The main causes of blunt trauma abdomen are road traffic accidents, fall from height or fall of object over body and assault. Majority of abdominal injuries encountered in emergency are due to blunt trauma abdomen. Majorities of blunt trauma abdomen cases $(75 \%)$ are related to motor vehicle collision. ${ }^{2}$
In the present era there are so many advanced diagnostic tools. Ultrasonography is regarded as investigation of choice for early diagnostic investigations in patients with suspected blunt trauma abdomen, whereas focused assessment of trauma by sonography (FAST) is considered investigation of choice in haemodynamically unstable patients. Patients with Free fluid in peritoneum and haemodynamically unstable need emergency laparotomy. The definitive diagnosis of blunt trauma abdomen is made by computerized tomography (CT) scan. A negative FAST without confirmation by contrast enhanced CT (CECT) Scan may result in missed intraabdominal injury. ${ }^{3,4}$ 
Rapid resuscitation is necessary to save unstable and salvageable patient with abdominal trauma. The primary goal is to assess patient for need for surgery.

\section{METHODS}

This was a cross sectional study. Patients admitted to department of surgery in UP Rural Institute of Medical Sciences and Research during period January 2015 to December 2015 were considered for the study, considering the exclusion and inclusion criteria. An informed consent with careful history along with thorough physical and general examination was done. Out of 110 admitted patients, 100 consecutive cases having history of blunt trauma abdomen and with regard to etiologies, clinical manifestations, diagnostic modalities, management and complication were taken for study.

Statistical analysis was carried out following data entry. Categorical data of the determinants were analyzed using the chi square test.

\section{RESULTS}

Out of 110 patients, 100 cases were taken for study. The results of study are given below.

In present study maximum cases were in 21-30 year (35\%). Average age was 25.1 year.

Table 1: Age wise distribution.

\begin{tabular}{|lll|}
\hline AGE (in year) & No. of cases & Percentage \\
\hline $1-10$ & 10 & 10 \\
\hline $11-20$ & 25 & 25 \\
\hline $21-30$ & 35 & 35 \\
\hline $31-40$ & 22 & 22 \\
\hline $41-50$ & 6 & 6 \\
\hline $51-60$ & 2 & 2 \\
\hline Total & 100 & \\
\hline
\end{tabular}

In present study, $75 \%$ were male and $25 \%$ were female. Male to female ratio was 3:1.

Table 2: Sex wise distribution.

\begin{tabular}{|lll|}
\hline Gender & No. of cases & Percentage \\
\hline Male & 75 & 75 \\
\hline Female & 25 & 25 \\
\hline Total & 100 & \\
\hline
\end{tabular}

In this study most common cause of blunt trauma abdomen was road traffic accident (60\%).

In this study, most common symptom was pain abdomen $(100 \%)$.
Table 3: Etiologies of injuries.

\begin{tabular}{|lll|}
\hline Nature of injury & No. of cases & Percentage \\
\hline Road traffic accident & 60 & 60 \\
\hline Fall from height & 25 & 25 \\
\hline Hit by blunt object & 8 & 8 \\
\hline Assault & 7 & 7 \\
\hline Total & 100 & \\
\hline
\end{tabular}

Table 5: Signs.

\begin{tabular}{|lll|}
\hline Signs & No. of cases & Percentage \\
\hline Tenderness & 95 & 95 \\
\hline Guarding & 50 & 50 \\
\hline Rigidity & 15 & 15 \\
\hline Bowel sound absent & 20 & 20 \\
\hline Shock & 20 & 20 \\
\hline
\end{tabular}

In this study USG was performed in $90 \%$, x-ray in about $95 \%$, while hemoglobin in nearly all patients.

Table 6: Investigations.

\begin{tabular}{|ll|}
\hline Investigations & No. of cases \\
\hline USG abdomen & 90 \\
\hline X- RAY erect abdomen & 95 \\
\hline $\mathrm{Hb} \%$ & 100 \\
\hline CECT abdomen & 65 \\
\hline
\end{tabular}

In present study, duration of stay ranged from 2-4 days. Mean duration of stay was 12 days. Mean duration of stay for operated cases was 16 days and for non- operated was 8.11 days.

Table 7: Duration of hospital stay (Including death).

\begin{tabular}{|lll|}
\hline Duration of stay (days) & No. of cases & Percentage \\
\hline $1-5$ & 15 & 15 \\
\hline $6-10$ & 30 & 30 \\
\hline $11-15$ & 25 & 25 \\
\hline $16-20$ & 26 & 26 \\
\hline$>20$ & 12 & 12 \\
\hline
\end{tabular}

In this study, $60 \%$ cases were managed surgically and $40 \%$ were conservatively.

In this study, spleen was most common involved in $28 \%$, liver was second most common organ injured.

Table 8: Management.

\begin{tabular}{|lll|}
\hline Treatment & No. of cases & Percentage \\
\hline Surgical & 60 & 60 \\
\hline Conservative & 40 & 40 \\
\hline Total & 100 & \\
\hline
\end{tabular}


Table 9: Organs involved.

\begin{tabular}{|lllll|}
\hline Organ & No. of cases & Percentage & Operative & Conservative \\
\hline Spleen & 28 & 28 & 12 & 16 \\
\hline Liver & 18 & 18 & 10 & - \\
\hline Small bowel & 16 & 16 & 16 & - \\
\hline Mesentry & 4 & 4 & 4 & - \\
\hline Large bowel & 4 & 4 & 4 & - \\
\hline Stomach & 4 & 4 & 4 & - \\
\hline Pancreas & 2 & 2 & 2 & - \\
\hline Urinary bladder & 2 & 2 & 2 & - \\
\hline Retroperitoneal hematoma & 2 & 2 & 2 & - \\
\hline
\end{tabular}

\section{DISCUSSION}

The most common cause of blunt injury abdomen is road traffic accidents $(60 \%)$ which are comparable to most other studies. Study by Curie et $\mathrm{al}^{5}$ also reported $58.6 \%$ cases of blunt injury to abdomen were due to RTA. Fall from height was found to be the second most common cause $(25 \%)$, other important causes were assault $(7 \%)$ and hit by object $(8 \%)$.

Maximum no. of cases were in $3^{\text {rd }}$ decade of life. This indicates trauma is more in young people. Average was 25.1 year. This study is comparable to Richard Curie. ${ }^{5}$ Which showed maximum no. of cases in $2^{\text {nd }}$ decade $(35 \%)$.

Male to female ratio was 3:1. Most common symptom was pain abdomen (100\%), vomiting in $40 \%$ followed by abdominal distension (20\%), urinary retention $(5 \%)$, and hematuria $(2 \%) .95 \%$ patients had abdominal tenderness at time of admission, local or generalized guarding was present in $50 \%$ cases, rigidity was present in $15 \%$ cases. This is comparable to study by Tripathi et al. ${ }^{6}$ Which reported tenderness as most common sign (30\%).

USG abdomen was done in $90 \%$ cases. USG was $81 \%$ sensitive and $100 \%$ specific.

Mean duration of hospital stay was 12.6 days. Mean duration for operated case was 16 days and that for nonoperated cases was 8.11 days. Maximum duration of hospital stay was 33 days for a patient who had burst abdomen. Spleen was most common injured (28\%), out of 28,16 were managed conservatively and 12 were operated. Splenectomy done in 6 cases and splenorraphy in 6 cases. R. Curie also reported $27.5 \%$ of cases had splenic injuries. Liver is second most common injured solid organ, out of which 10 were operated and 8 were managed conservatively. Small bowel involved in $16 \%$ cases.

Out of $100 \%$ cases, 60 were managed conservatively and 40 conservatively. Wound infection was most common complication in 8 cases followed by 2 cases of pelvic abscess, pneumonia, anastomotic leakage and intestinal obstruction. This is comparable to a study by Jolly et al. ${ }^{7}$ Which shows wound infection in $14 \%$ of cases.

$5 \%$ cases were ended in mortality. Septicemia was most common cause of death. Sudden cardiac arrest was seen in 1 patient.

\section{CONCLUSION}

Blunt trauma to abdomen is on rise due to excessive use of motor vehicles. It poses a therapeutic and diagnostic dilemma for the attending surgeon due to wide range of clinical manifestations ranging from no early physical finding to progression to shock. So, the Trauma Surgeon should rely on his physical findings in association with use of modalities like $\mathrm{x}$-ray abdomen, USG abdomen, and CECT abdomen. Hollow viscous perforations are relatively easy to pick on $\mathrm{x}$-ray. But solid organ injuries are sometimes difficult to diagnose due to restricted use of modern amenities like CT scan in India. From our study we conclude that in a haemodynamically stable patients with solid organ injury conservative management can be tried and non- operative management is associated with less complication and morbidity.

Funding: No funding sources

Conflict of interest: None declared

Ethical approval: The study was approved by the institutional ethics committee

\section{REFERENCES}

1. Hemmila MR, Wahl WL. Management of the injured patient. Current surgical diagnosis and treatment. McGraw-Hill Medical; 2008:227-228.

2. Isenhour JL, Marx J. Advances in abdominal trauma. Emerg Med Clin North Am. 2007;25:713.

3. Stengel D, Bauwens K, Rademacher G. Emergency ultrasound based algorithms for diagnosing blunt abdominal trauma. Cochrane Database Syst Rev. 2013;31:7.

4. Natranjan B, Gupta PK, Cemaj S. FAST Scan Surgery. 2010;148:695-700.

5. Curie RA, Watne AI. Blunt abdominal trauma, American journal of surg. 1964;107:321-7. 
6. Tripathi MD, Srivastav RD, Nagar AM, Pratap VK, Dwivedi SC. Blunt abdominal trauma with special references to early detection of visceral injuries. Indian I Surg. 1991;53(5):179-84.

7. Jolly S, Upadhyay M, Jam BL. Blunt trauma abdomen. A clinical study of 100 cases. Indian I Surg. 1993:290-93.
Cite this article as: Singh SP, Gupta V, Singh SP, Verma R, Gupta P, Kumar A, Bagaria D, Pandey J, Kumar G, Singh M. Pattern of injury of blunt trauma abdomen in rural population. Int Surg J 2016;3:497500 . 